\title{
A national study on the use of opioid analgesics in dentistry
}

\section{Patrícia Azevedo LINO(a) \\ Woosung SOHN(b) \\ Astha SINGHAL (c) \\ Maria Auxiliadora Parreiras \\ MARTINS(d) iD}

Maria Elisa de Souza e SILVA(e)

Mauro Henrique Nogueira

Guimarães de ABREU(a)

(a) Universidade Federal de Minas Gerais UFMG, School of Dentistry, Department of Community and Preventive Dentistry, Belo Horizonte, MG, Brazil.

(b) The University of Sidney, School of Medicine, Sidney, New South Wales, Australia.

(c)Boston University, Henry M. Goldman School of Dental Medicine, Department of Health Policy \& Health Services Research, Boston, Massachusetts, USA.

(d) Universidade Federal de Minas Gerais UFMG, School of Pharmacy, Department of Pharmaceutical Products, Belo Horizonte, MG, Brazil.

(e) Universidade Federal de Minas Gerais UFMG, School of Dentistry, Department of Operative Dentistry, Belo Horizonte, MG, Brazil.

Declaration of Interests: The authors certify that they have no commercial or associative interest that represents a conflict of interest in connection with the manuscript.

\section{Corresponding Author:}

Mauro Henrique Nogueira Guimarães de Abreu E-mail: maurohenriqueabreu@gmail.com

htpps://doi.org/10.1590/1807-3107bor-2019.vol33.0076

Submitted: February 21, 2019

Accepted for publication: June 11, 2019

Last revision: June 24, 2019
Abstract: The aim of this study was to assess the frequency of opioid analgesics prescribed by Brazilian dentists, potential regional differences and their association with socioeconomic and health-related factors. Data for all opioid prescriptions by dentists was obtained from the 2012 database of the National Controlled Substances Management System, regulated by the Brazilian Health Surveillance Agency. The number of defined daily doses (DDD) and DDDs per 1,000 inhabitants per day for each Brazilian state were calculated as the primary outcomes. DDDs were compared by regions and Brazilian states. Spearman's rho correlation coefficient was used to determine the influence of the states' characteristics, such as the Human Development Index; poverty; education; number of dentists per 100,000 inhabitants; visit to the dentist; dental care plan; good or very good oral health; number of pharmaceutical establishments per 100,000/inhabitants; and ability to get all prescribed medications. Data analysis was performed using IBM SPSS Statistics 25.0. A total of 141,161 prescriptions for opioids analgesics by 36,929 dentists were recorded, corresponding to 658,855 doses of opioids dispensed in 2012. The most commonly dispensed opioids were codeine associated with paracetamol $(83.2 \% ; n=117,493)$. The national DDDs per 1,000 inhabitants per day was 0.0093 (range: $0.0002-0.0216$ ). DDD per 1,000 inhabitants per day was positively associated to visits to dentists ( $\mathrm{rs}=0.630 ; \mathrm{P}<0.001)$ and inversely associated to poverty ( $\mathrm{rs}=-0.624$; $\mathrm{p}=0.001$ ). There are significant differences in opioid prescriptions in dentistry among the Brazilian states. These differences may be associated with non-clinical factors.

Keywords: Analgesics, Opioid; Prescription Drugs; Dentistry; Healthcare Disparities; Dental Care.

\section{Introduction}

The management of pain is very common in the dental practice. ${ }^{1}$ When drug therapy is required, opioid analgesics are not usually the first choice, however they should be considered as an alternative in specific

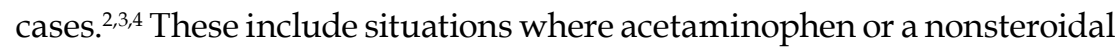
anti-inflammatory drug (NSAID) are contraindicated. The World Health Organisation reinforces that opioid analgesics are an additional medication to other first-choice non-opioids, in cases where they do not act enough. ${ }^{5}$ 
Opioid use has increased in dental practice in the last few decades. ${ }^{6}$ Studies also report an increased prevalence of opioid addiction and a parallel increase in opioid overdose deaths. ${ }^{7}$ As one might expect, prescribers play an important role in controlling these addiction problems. ${ }^{8}$ However, on the other hand, millions of people worldwide suffer from untreated pain, this great need for pain control is found in the developing world, especially among the poor, elderly, mentally ill, children, women, and racial/ethnic minorities. ${ }^{9}$ The use of opioid analgesics has increased in different geographic areas and in different scenarios. However they coexist with a great concern in some regions where with excessive opioid use, while other regions experience difficulty accessing this class of drugs. ${ }^{10}$

Rational drug therapy aims to select pain-relief or pain-control drugs while minimising possible adverse effects. National drug surveillance systems may collaborate with actions promoting rational drug use. Some healthcare systems worldwide have databases that enable monitoring and comparisons between various pharmaceutical drugs usage. These drug-dispensing data enable the identifying of patterns of drug prescription adopted by healthcare professionals. In Brazil, opioid analgesics are controlled by the Brazilian Health Regulatory Agency (Agência Nacional de Vigilância Sanitária - Anvisa) and according to current legislation these drugs require a prescription to be dispensed. ${ }^{11}$

In Brazil, accessing these medications involves a sequence of events. Firstly, consultation with a dentist, then, the dentist prescribes the opioid analgesic when it is needed and finally access to medication. ${ }^{11}$ Socioeconomic conditions and cost of opioids can also interfere in the access to medication. ${ }^{12}$

Brazil has an extensive area, with different socioeconomic and health characteristics among regions. Current studies demonstrate associations between social and economic inequalities and health, thus monitoring health inequalities has become an essential feature of measuring national health progress and development that can guide public policies. ${ }^{13}$

Socioeconomic factors, such as poverty, Human Development Index (HDI), education and healthrelated factors, such as the number of dentists, access to oral health services and to medicines could be associated to opioid use in the population. Considering the potential impact of opioid use on population, the relevant role of prescribers in the rational use and the few epidemiological studies exploring the role of dentistry on opioid prescriptions in Brazil, the objective of this study was to provide national data on the use of opioid analgesic in dentistry and to explore its association with socioeconomic and health-related factors. The null hypothesis was that socioeconomic and health-related factors would not affect the use of opioid analgesic in dentistry.

\section{Methodology}

This cross-sectional study investigated the opioid analgesic prescription by Brazilian dentists dispensed during the year 2012. The database was provided by the National Controlled Substances Management System (Sistema Nacional de Gerenciamento de Produtos Controlados - SNGPC) of Brazilian Health Regulatory Agency, which surveys private drugstores. This study was approved by the Ethics Committee of the Federal University of Minas Gerais (Universidade Federal de Minas Gerais - UFMG) under number CAAE-24383913.9.0000.5149.

All opioid analgesics prescriptions dispensed by Brazilian pharmacies in 2012 were made available by SNGPC for data analysis. The following variables were collected from the original database: prescribed drugs, drug presentation and quantity prescribed of each drug, Brazilian state where the product was sold and the dentist's code. The drugs were classified according to the Anatomical Therapeutic Chemical (ATC) Classification System of the World Health Organisation (WHO) Collaborating Centre for Drug Statistics and Methodology. ${ }^{14}$

For population analysis, a statistical measure of drug consumption that enables researchers to assess drug consumption trends and to perform comparisons between population groups is the defined daily dose (DDD). Each formulation (and per route of administration is assigned a daily dose by WHO Center, that is the mg (or other units) per day an adult needs for the desired therapeutic effect, based on the current data and guidelines. Then, we 
calculated i) the number of DDDs for each prescribed opioid and ii) the DDDs per 1,000 inhabitants per day for each Brazilian state: a) The number of DDDs was obtained with the multiplication of (aa) number of packages by (ab) pharmaceutical forms' number per package and (ac) drug active ingredients' quantity per pharmaceutical form. Lastly, the product of this multiplication was divided by the DDD of each drug according to ATC; b) The "DDDs per 1,000 inhabitants per day" provides an estimate of the proportion of the population within a defined area treated daily with a certain drug. The following formula was used to calculate the DDDs per 1,000 inhabitants per day: (number of DDDs x 1,000) / (inhabitants x 365). ${ }^{14,15,16}$

Multiple sources of data were used to identify Brazilian states socioeconomic and health-related factors, The Atlas of Human Development in Brazil (Atlas de Desenvolvimento Humano no Brasil) provided the HDI, the indicator of poverty and education. ${ }^{17}$ The HDI was proposed by the United Nations Development Programme and combines three aspects for the life: the opportunity for a long and healthy life (health); the access to knowledge (education); and income. For health information, the nationwide household National
Health Survey (Pesquisa Nacional de Saúde - PNS) provides important state level information, such as dental visits, dental care plan, proportion of population that considers their oral health as good or very good and ability to get all prescribed medications. ${ }^{18}$ The number of dentists, by Brazilian state, was provided by the Federal Council of Dentistry ${ }^{19}$ (Conselho Federal de Odontologia - CFO), and the number of inhabitants was obtained from the Brazilian Institute of Geography and Statistics ${ }^{15}$ (Instituto Brasileiro de Geografia e Estatística - IBGE). The number of pharmaceutical establishments per 100,000 inhabitants (registered in SNGPC) was supplied by the Brazilian Health Regulatory Agency ${ }^{11}$ (Table 1).

Taking into account the events involved with acquiring opioid analgesics by a population, variables were organised into three groups (Table 1):

a. Socioeconomics: poverty; HDI; and education;

b. Health - Oral Health: number of dentists per 100,000 inhabitants; visit to the dentist; dental care plan; and good or very good oral health;

c. Health-Medications: number of pharmaceutical establishments per 100,000 inhabitants; and ability to get all prescribed medications.

Table 1. List of variables.

\begin{tabular}{|c|c|c|}
\hline Variables & Definition & Source \\
\hline \multicolumn{3}{|l|}{ Socioeconomic } \\
\hline Poverty & $\begin{array}{l}\text { Proportion of individuals with per capita household } \\
\text { income less than } \$ 145.28 \text { ( } 1 \$=1.76 \text { Brazilian Reais) }\end{array}$ & Atlas of Human Development in Brazil \\
\hline Human Development Index & $\begin{array}{l}\text { Geometric mean of the three dimensions: longevity, } \\
\text { education and income. Range from } 0 \text { to } 1 .\end{array}$ & Atlas of Human Development in Brazil \\
\hline Education & $\begin{array}{c}\text { Average years of study for persons with at least } 25 \\
\text { years of age }\end{array}$ & Atlas of Human Development in Brazil \\
\hline \multicolumn{3}{|l|}{ Health - Oral Health } \\
\hline $\begin{array}{l}\text { Number of dentists per } 100,000 \\
\text { inhabitants }\end{array}$ & $\begin{array}{c}\text { Total number of dentists registered on Federal Council } \\
\text { of Dentistry }\end{array}$ & Federal Council of Dentistry \\
\hline Visit to dentists & $\begin{array}{l}\text { Proportion of population who visited the dentist in the } \\
\qquad \text { last } 12 \text { months }\end{array}$ & Pesquisa Nacional de Saúde \\
\hline Dental care plan & $\begin{array}{l}\text { Proportion of population with some plan only for } \\
\text { dental care }\end{array}$ & Pesquisa Nacional de Saúde \\
\hline Consider oral health good or very good & $\begin{array}{l}\text { Proportion of population with } 18 \text { years of age or older } \\
\text { that consider their oral health as good or very good }\end{array}$ & Pesquisa Nacional de Saúde \\
\hline \multicolumn{3}{|l|}{ Health - Medications } \\
\hline $\begin{array}{l}\text { Number of pharmaceutical establishments } \\
\text { per } 100,000 \text { inhabitants }\end{array}$ & $\begin{array}{l}\text { Total number of pharmaceutical establishments divided } \\
\text { by } 100,000 \text { inhabitants }\end{array}$ & Brazilian Health Regulatory Agency \\
\hline Ability to get all medications prescribed & $\begin{array}{l}\text { Proportion of population that were able to obtain all } \\
\text { the drugs prescribed in their last health consultation }\end{array}$ & Pesquisa Nacional de Saúde \\
\hline
\end{tabular}


A descriptive statistical analysis was performed, including the calculation of proportions and measures of central tendency and variability. To understand whether these state-level covariates were associated to values of DDDs per 1,000 inhabitants per day, non-parametric correlation tests were performed (Spearman's rho correlation coefficient, 2-tailed $-r_{s}$ ). Data analysis was performed using the IBM SPSS Statistics 25.0 statistical software.

\section{Results}

A total of 141,161 prescriptions for opioids analgesics were made by 36,929 dentists. A total of 160,627 packages were dispensed $(90.3 \%$ with 1 package). The frequency of opioid prescription type was codeine associated to paracetamol $n=117,493(83.2 \%)$, tramadol $n=13,562(9.6 \%)$, codeine and other non-opioid analgesics $\mathrm{n}=4,308(3.1 \%)$, tramadol and paracetamol $n=4,297(3.0 \%)$, codeine $\mathrm{n}=1,056(0.7 \%)$, oxycodone $\mathrm{n}=390(0.3 \%)$, morphine $\mathrm{n}=50(<0.001 \%)$, fentanyl $\mathrm{n}=4(<0.001 \%)$ and hydromorphone $\mathrm{n}=1(<0.001 \%)$. The national mean of opioid prescriptions by dentists was 3.82 prescriptions (50.6\% of dentists prescribed at least 12 times during the year). These data are not tabulated.

Brazilian state-level results show that the prescription frequencies ranged from 93 to 39,105 prescriptions, the number of opioid packages ranged from 108 to 46,977 , the number of DDD ranged from 441.9 to $18,4233.9$ and the mean number of dentist-prescribed prescriptions ranged from 1.99 to 5.06 (Table 2).

The socioeconomic and health indicators differences between the Brazilian regions are presented in Table 3. The North and Northeast states' proportions of individuals with per capita household income less than $\$ 145.28$ ranged from $27.4 \%$ to $56.9 \%$, while South, Southeast and Midwest states' values ranged from $8.0 \%$ to $20.2 \%$ of the population. The proportion of the population that visited the dentist in the last 12 months in states of the North and Northeast varied from $28.5 \%$ to $43.7 \%$, while in states of South, Southeast and Midwest region results ranged from $39.2 \%$ to $54.1 \%$ of the population. The proportion of individuals that were able to obtain all the drugs prescribed in the last health consultation ranged from $63.6 \%$ (RR - North) to $86.9 \%$ (ES - Southeast).

There was a large difference between the prescription rates among Brazilian states. The national DDDs per 1,000 inhabitants per day was 0.0093 , with the lowest value being 0.0002 (MA - Northeast) and the highest value 0.0216 (RS - South). There are clearly two groups within the country. The first group with seven states that presented high prescription rates of opioid analgesics dispensed to patients (range: 0.0077-0.0216 DDDs per 1,000 inhabitants per day) and the second group with twenty states that had low prescription rates (range: 0.0002-0.0050). States with high values correspond to the seven states with a darker colour (RS, MG, SC, PR, BA, SP, DF) on the map, which illustrates how these states are distributed within the Brazilian territory. Five states with high prescriptions rates are in the South and Southeast regions (Figure).

Table 4 shows the result of factors associated to the quantities of opioid analgesics sold in Brazilian states. All analysed covariates were associated to differences in DDD values in state level analysis ( $n=27 ; \mathrm{p}<0.05)$. DDD per 1,000 inhabitants per day was inversely associated to poverty and positively associated to the other factors $(\mathrm{n}=27 ; \mathrm{p}<0.05)$. In the socioeconomic category, the factor that had the most significant association with the amount of opioid analgesics dispensed was poverty $\left(r_{s}=-0.624 ; p=0.001\right)$. In the oral health category, visiting the dentists in the last 12 months was the most significant factor $\left(\mathrm{r}_{\mathrm{s}}=0.630\right.$; $p<0.001)$. Finally, in the medications category, the number of pharmaceutical establishments per $100,000 /$ inhabitants was associated to the quantities of opioids $\left(r_{s}=0.505 ; p=0.007\right)$.

Table 4 also shows how covariates act when the data are stratified according to the value of DDDs per 1,000 inhabitants per day. States were categorised as "low" and "high", with the cut-off point being the third quartile value. States with DDDs above the third quartile were classified as high $(n=7)$ while states below the third quartile were classified as low $(n=20)$. This analysis is important because there was a large difference between the prescription rates. When the data are stratified, in Brazilian states with low prescription rates $(n=20)$, the association 
Table 2. Descriptive statistics on the opioid analgesics prescribed by Brazilian dentists dispensed by Brazilian state in 2012 .

\begin{tabular}{|c|c|c|c|c|c|}
\hline Region & Brazilian state & Frequency of prescription ${ }^{a}$ & Prescription per dentist $t^{b}$ mean (min-max) & Number of packages & Number of DDDs \\
\hline \multirow{4}{*}{ Midwest } & DF & $1430(1.0 \%)$ & $3.43(1-198)$ & 1691 & 7464.0 \\
\hline & GO & $2210(1.6 \%)$ & $3.63(1-92)$ & 2607 & 11227.9 \\
\hline & MS & $768(0.5 \%)$ & $3.14(1-123)$ & 837 & 2850.1 \\
\hline & MT & $617(0.4 \%)$ & $3.94(1-61)$ & 680 & 2447.3 \\
\hline \multirow{7}{*}{ North } & $A C$ & $93(0.1 \%)$ & $2.58(1-27)$ & 108 & 441.9 \\
\hline & AM & $230(0.2 \%)$ & $2.95(1-46)$ & 252 & 1216.9 \\
\hline & AP & $133(0.1 \%)$ & $4.26(1-31)$ & 138 & 635.0 \\
\hline & PA & 1759 (1.2\%) & $4.07(1-72)$ & 1927 & 7808.0 \\
\hline & $\mathrm{RO}$ & $203(0.1 \%)$ & $3.14(1-43)$ & 222 & 878.7 \\
\hline & RR & $164(0.1 \%)$ & $2.88(1-20)$ & 229 & 833.3 \\
\hline & TO & $266(0.2 \%)$ & $2.95(1-37)$ & 300 & 1511.3 \\
\hline \multirow{9}{*}{ Northeast } & $\mathrm{AL}$ & 677 (0.5\%) & $3.01(1-42)$ & 737 & 2984.5 \\
\hline & BA & 14311 (10.1\%) & $5.06(1-157)$ & 15076 & 62575.0 \\
\hline & CE & 1929 (1.4\%) & $3.26(1-124)$ & 2207 & 9699.9 \\
\hline & MA & 109 (0.1\%) & $2.12(1-18)$ & 142 & 587.0 \\
\hline & PB & 785 (0.6\%) & 2.99 (1-98) & 990 & 3804.0 \\
\hline & $\mathrm{PE}$ & $1770(1.3 \%)$ & $2.90(1-85)$ & 2099 & 8766.2 \\
\hline & $\mathrm{Pl}$ & 177 (0.1\%) & $2.75(1-50)$ & 223 & 756.7 \\
\hline & RN & $1018(0.7 \%)$ & $4.07(1-81)$ & 1112 & 4385.0 \\
\hline & SE & 753 (0.5\%) & $3.28(1-77)$ & 818 & 3245.8 \\
\hline \multirow{3}{*}{ South } & PR & 11430 (8.1\%) & $3.55(1-144)$ & 12604 & 53943.3 \\
\hline & RS & 17970 (12.7\%) & $4.27(1-203)$ & 20275 & 85045.5 \\
\hline & SC & 8210 (5.8\%) & $3.84(1-188)$ & 9253 & 38934.4 \\
\hline \multirow{4}{*}{ Southeast } & ES & $468(0.3 \%)$ & $1.99(1-24)$ & 617 & 2489.9 \\
\hline & MG & 30072 (21.3\%) & $4.78(1-340)$ & 32594 & 137559.6 \\
\hline & RJ & 4504 (3.2\%) & $2.43(1-160)$ & 5912 & 22529.4 \\
\hline & SP & 39105 (27.7\%) & $3.36(1-452)$ & 46977 & 184233.9 \\
\hline
\end{tabular}

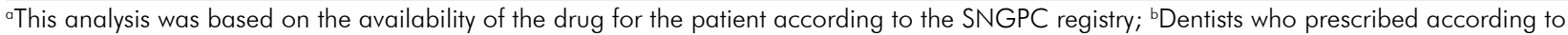
Brazilian state of professional registration.

was significant with the vulnerability to poverty $\left(r_{s}=-0.489 ; p=0.029\right)$ and visit to dentists $\left(r_{s}=0.466\right.$; $\mathrm{p}=0.038)$. In Brazilian states with high prescription rates $(\mathrm{n}=7)$, the significant association was with dental care plan $\left(\mathrm{r}_{\mathrm{s}}=-0.847 ; \mathrm{p}=0.016\right)$.

When we evaluate all states, the correlation coefficients were positive for HDI, education, number of dentists per 100,000/inhabitants and dental care plan. This is maintained in the stratified analysis where states presented low prescription rates. But in states with high prescription rates, the correlation coefficients were negative, thus, a better HDI, more years of study and more dentists for the population are associated to lower DDD values. Vulnerability to poverty was consistently negatively associated to DDD.
Regarding to dental care plan, in the analysis with all states $(n=27)$ and states with low prescription rates $(n=20)$, the correlation coefficient was positive, but in the states with high prescription rates was negative and significant $\left(r_{s}=-0.847 ; p=0.016\right)$. It is possible to see that factors can act differently when states are stratified according to prescription rates (Table 4).

\section{Discussion}

This study found a low amount of opioids prescribed by Brazilian dentists, with different rates among states. Socioeconomic and health-related factors influenced the quantities of opioids dispensing in Brazilian states. 
Table 3. Socioeconomic, oral health and medication indicators by Brazilian states.

\begin{tabular}{|c|c|c|c|c|c|c|c|c|c|c|}
\hline Region & State & Poverty & $\mathrm{HDI}$ & Education & $\begin{array}{c}\text { Number of } \\
\text { dentists per } \\
100,000 / \text { inhabitants }\end{array}$ & $\begin{array}{l}\text { Visit to } \\
\text { dentists }\end{array}$ & $\begin{array}{l}\text { Dental } \\
\text { care } \\
\text { plan }\end{array}$ & $\begin{array}{l}\text { Consider oral } \\
\text { health good or } \\
\text { very good }\end{array}$ & $\begin{array}{c}\text { Number of } \\
\text { pharmaceutical } \\
\text { establishments per } \\
100,000 / \text { inhabitants }\end{array}$ & $\begin{array}{l}\text { Ability to get } \\
\text { all medications } \\
\text { prescribed }\end{array}$ \\
\hline \multirow{4}{*}{ Midwest } & DF & $15.0 \%$ & 0.827 & 10.8 & 233 & $51.9 \%$ & $6.8 \%$ & $74.0 \%$ & 33 & $80.2 \%$ \\
\hline & GO & $16.6 \%$ & 0.745 & 8.6 & 149 & $42.4 \%$ & $6.2 \%$ & $67.7 \%$ & 52 & $84.4 \%$ \\
\hline & MS & $15.5 \%$ & 0.746 & 8.7 & 149 & $47.5 \%$ & $2.5 \%$ & $71.2 \%$ & 33 & $85.9 \%$ \\
\hline & MT & $19.0 \%$ & 0.755 & 8.4 & 137 & $41.8 \%$ & $4.7 \%$ & $64.6 \%$ & 38 & $77.4 \%$ \\
\hline \multirow{7}{*}{ North } & $A C$ & $42.3 \%$ & 0.696 & 8.1 & 84 & $36.1 \%$ & $1.4 \%$ & $64.1 \%$ & 24 & $78.1 \%$ \\
\hline & $A M$ & $42.9 \%$ & 0.679 & 8.8 & 98 & $42.1 \%$ & $4.8 \%$ & $66.3 \%$ & 7 & $73.4 \%$ \\
\hline & AP & $40.5 \%$ & 0.707 & 9.2 & 90 & $30.7 \%$ & $3.9 \%$ & $66.4 \%$ & 13 & $79.7 \%$ \\
\hline & PA & $43.5 \%$ & 0.659 & 7.7 & 61 & $30.1 \%$ & $3.4 \%$ & $56.1 \%$ & 12 & $76.4 \%$ \\
\hline & $\mathrm{RO}$ & $27.4 \%$ & 0.698 & 7.9 & 117 & $36.3 \%$ & $2.1 \%$ & $58.3 \%$ & 34 & $82.6 \%$ \\
\hline & RR & $37.0 \%$ & 0.729 & 9.6 & 137 & $39.9 \%$ & $2.0 \%$ & $65.9 \%$ & 17 & $63.6 \%$ \\
\hline & TO & $34.0 \%$ & 0.711 & 7.9 & 132 & $36.0 \%$ & $2.4 \%$ & $58.9 \%$ & 27 & $73.9 \%$ \\
\hline \multirow{9}{*}{ Northeast } & $\mathrm{AL}$ & $50.5 \%$ & 0.644 & 6.6 & 84 & $34.8 \%$ & $3.4 \%$ & $57.0 \%$ & 21 & $74.7 \%$ \\
\hline & $\mathrm{BA}$ & $44.0 \%$ & 0.682 & 7.4 & 78 & $35.9 \%$ & $5.4 \%$ & $57.7 \%$ & 18 & $81.8 \%$ \\
\hline & CE & $44.2 \%$ & 0.704 & 7.2 & 75 & $37.3 \%$ & $3.2 \%$ & $61.8 \%$ & 15 & $81.3 \%$ \\
\hline & MA & $56.9 \%$ & 0.650 & 6.7 & 57 & $28.5 \%$ & $1.6 \%$ & $50.7 \%$ & 11 & $79.1 \%$ \\
\hline & PB & $40.8 \%$ & 0.682 & 7.3 & 111 & $43.6 \%$ & $3.2 \%$ & $60.0 \%$ & 27 & $82.1 \%$ \\
\hline & PE & $39.8 \%$ & 0.694 & 7.7 & 83 & $42.5 \%$ & $3.2 \%$ & $61.7 \%$ & 18 & $83.0 \%$ \\
\hline & $\mathrm{Pl}$ & $44.9 \%$ & 0.664 & 6.6 & 92 & $36.9 \%$ & $1.0 \%$ & $57.9 \%$ & 20 & $74.5 \%$ \\
\hline & RN & $36.8 \%$ & 0.715 & 7.8 & 106 & $43.7 \%$ & $3.9 \%$ & $61.5 \%$ & 29 & $78.5 \%$ \\
\hline & SE & $39.7 \%$ & 0.688 & 7.4 & 85 & $40.2 \%$ & $4.2 \%$ & $61.8 \%$ & 22 & $84.4 \%$ \\
\hline \multirow{3}{*}{ South } & PR & $13.9 \%$ & 0.774 & 8.9 & 165 & $49.7 \%$ & $6.8 \%$ & $71.3 \%$ & 41 & $86.1 \%$ \\
\hline & RS & $14.4 \%$ & 0.757 & 8.7 & 158 & $52.7 \%$ & $3.9 \%$ & $73.4 \%$ & 42 & $84.5 \%$ \\
\hline & SC & $8.0 \%$ & 0.797 & 9.1 & 167 & $54.1 \%$ & $4.6 \%$ & $71.5 \%$ & 42 & $83.4 \%$ \\
\hline \multirow{4}{*}{ Southeast } & ES & $18.7 \%$ & 0.769 & 8.8 & 141 & $39.2 \%$ & $4.3 \%$ & $66.3 \%$ & 39 & $86.9 \%$ \\
\hline & $M G$ & $20.2 \%$ & 0.754 & 8.3 & 162 & $43.2 \%$ & $3.2 \%$ & $69.6 \%$ & 39 & $83.0 \%$ \\
\hline & RJ & $18.6 \%$ & 0.762 & 9.7 & 183 & $42.2 \%$ & $7.2 \%$ & $71.6 \%$ & 24 & $82.8 \%$ \\
\hline & SP & $11.3 \%$ & 0.808 & 9.7 & 190 & $53.9 \%$ & $8.0 \%$ & $74.1 \%$ & 30 & $83.0 \%$ \\
\hline
\end{tabular}

Sources: Atlas of Human Development in Brazil, PNS, IBGE, CFO and Anvisa.

The quantities of opioid analgesics prescribed by dentists and dispensed was low, mainly when compared to the medical prescriptions of some countries. ${ }^{20-23}$ These data are in agreement with a recently published study, which found lower values of opioid use in South America and addressed possible barriers to access to these drugs. ${ }^{10}$ Most of the prescriptions were for a short period of time, because $90.3 \%$ of prescriptions had only one package and $62.3 \%$ with four DDD by prescription (four days of treatment). Short-term use was gratifying to find because, of a decreased risk of chemical dependence (opioid misuse or abuse) in this population. Besides the risk of chemical dependence, opioid analgesics may increase or decrease the potency of other drugs. Opioids may interact with some antibiotics, benzodiazepines, centrally acting sedative drugs, antidepressants and alcohol, they should be prescribed with caution to individuals with obstructive sleep apnoea. ${ }^{24,25}$ There is some evidence that opioid users are at a higher risk of traffic accidents. ${ }^{26} \mathrm{~A}$ systematic review on prescriber behaviour identified five ways in which opioid prescribers' behaviour may have played a role in increased opioid-related mortality: prescribing more opioids, prescribing higher doses of opioids, prescribing oxycodone, prescribing methadone and prescribing at high volumes. ${ }^{8}$ 


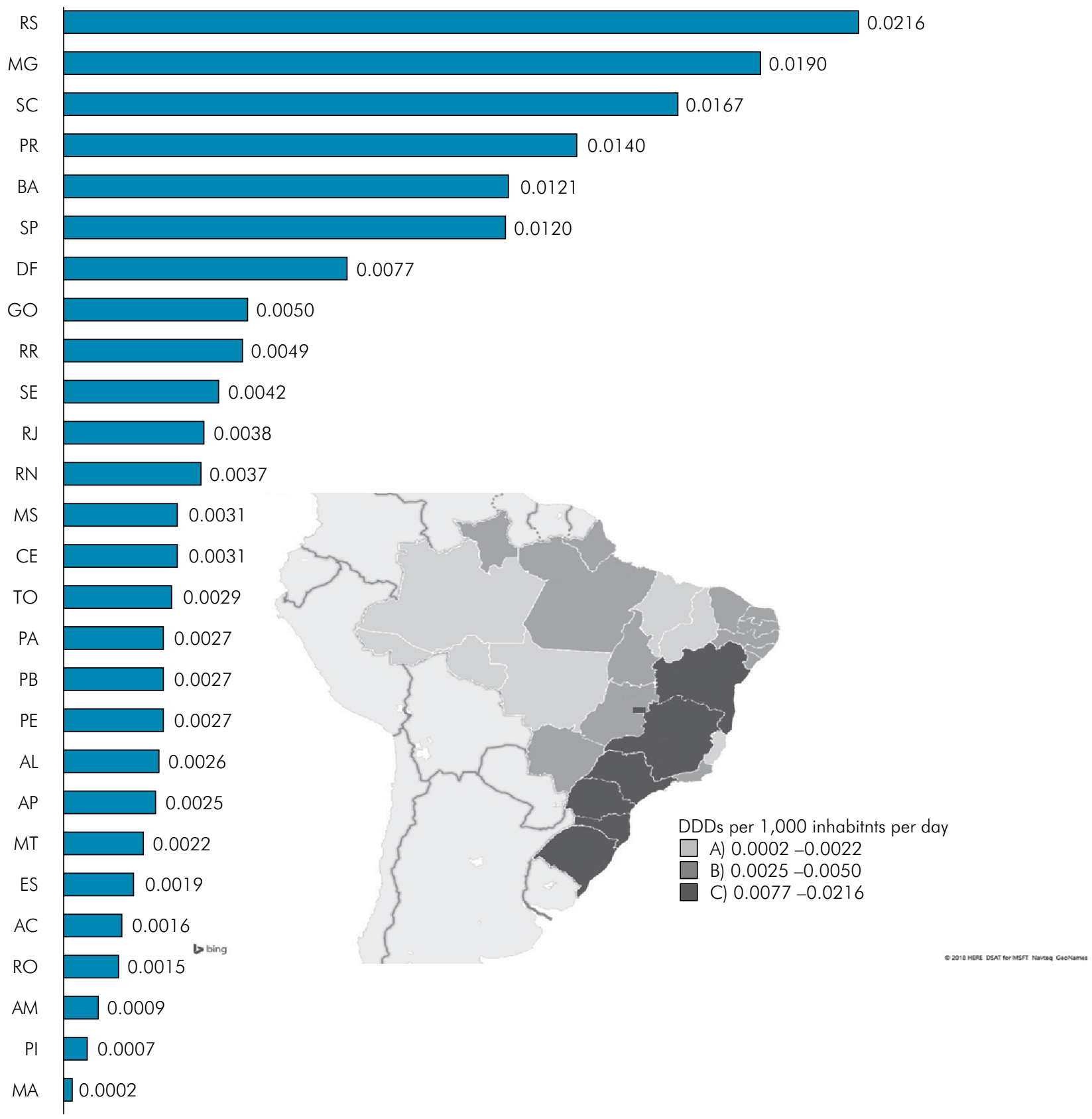

Figure. Distribution of DDDs per 1,000 inhabitants per day by Brazilian states.

DDDs per 1,000 inhabitants per day demonstrated atypical distributions within the Brazilian territory, with large variations between the largest and smallest state values and with the highest values concentrated in southern and south-eastern states. We identify two types of dental opioid prescription regions in the Brazilian states. A small group of states with high dispensing rates and a large group with low dispensing rates. One possible explanation for this divergence could be the diversity found within the territory, where some regions present better indicators than others. Brazilian regions experience very different socioeconomic indicators, dental access and access to medications. As seen in this study, regions with better socioeconomic indicators, such as south and southeast regions, also show greater access to dentists and more 
Table 4. Correlation between socioeconomic/health factors and quantities of opioid analgesics dispensing in Brazilian states, 2012.

\begin{tabular}{|c|c|c|c|c|c|c|}
\hline \multirow[b]{2}{*}{ Covariates } & \multicolumn{2}{|c|}{ All Brazilian states $(n=27)$} & \multicolumn{2}{|c|}{ States with low ${ }^{a}$ DDD $(n=20)$} & \multicolumn{2}{|c|}{ States with high ${ }^{\circ}$ DD $(n=7)$} \\
\hline & $\begin{array}{l}\text { Spearman's } \\
\text { correlation coefficient }\end{array}$ & $\begin{array}{l}\mathrm{p} \text {-value } \\
\text { (2-tailed) }\end{array}$ & $\begin{array}{l}\text { Spearman's } \\
\text { correlation coefficient }\end{array}$ & $\begin{array}{l}\mathrm{p} \text {-value } \\
\text { (2-tailed) }\end{array}$ & $\begin{array}{l}\text { Spearman's } \\
\text { correlation coefficient }\end{array}$ & $\begin{array}{l}\text { p-value } \\
\text { (2-tailed) }\end{array}$ \\
\hline \multicolumn{7}{|l|}{ Socioeconomic } \\
\hline Poverty & -0.624 & 0.001 & -0.489 & 0.029 & -0.036 & 0.939 \\
\hline Human Development Index & 0.603 & 0.001 & 0.442 & 0.051 & -0.571 & 0.180 \\
\hline Education & 0.412 & 0.033 & 0.266 & 0.258 & -0.571 & 0.180 \\
\hline \multicolumn{7}{|l|}{ Health - oral health } \\
\hline $\begin{array}{l}\text { Number of dentists per } \\
100,000 / \text { inhabitants }\end{array}$ & 0.576 & 0.002 & 0.388 & 0.091 & -0.607 & 0.148 \\
\hline Visit to dentists & 0.630 & $<0.001$ & 0.466 & 0.038 & 0.036 & 0.939 \\
\hline Dental care plan & 0.493 & 0.009 & 0.344 & 0.137 & -0.847 & 0.016 \\
\hline $\begin{array}{l}\text { Consider oral health good } \\
\text { or very good }\end{array}$ & 0.585 & 0.001 & 0.394 & 0.086 & -0.357 & 0.432 \\
\hline \multicolumn{7}{|l|}{ Health - medicines } \\
\hline $\begin{array}{l}\text { Number of pharmaceutical } \\
\text { establishments per } \\
100,000 / \text { inhabitants }\end{array}$ & 0.505 & 0.007 & 0.247 & 0.294 & 0.721 & 0.068 \\
\hline $\begin{array}{l}\text { Ability to get all } \\
\text { medications prescribed }\end{array}$ & 0.484 & 0.010 & 0.251 & 0.285 & 0.649 & 0.115 \\
\hline
\end{tabular}

'The cut-off point was the third quartile. It refers to an internal comparison (within the Brazilian territory), we are not comparing these values with of other countries.

prescriptions. The study results are in agreement with previous studies which also showed that these regions have better indicators. ${ }^{27,28,29}$ Differences in the quantities of opioid analgesics dispensed may reflect the existence of differences in access to these drugs between states. Most Brazilian states have relatively low dispensing rates of opioid analgesics for dental care purposes. However, the seven states with the highest DDDs per 1,000 inhabitants per day accumulated $86.8 \%$ of the total prescriptions.

All analysed variables were associated to differences in DDD values in the state level analysis $(n=27)$, but it is important to point out the association of the quantity of opioids prescribed with access to the dentist in the last 12 months and poverty. The Brazilian states with increased access to the dentists, presented a higher amount of sales of opioid analgesics. States with the highest proportion of people living with less than 145.28 US dollar presented lower sales of opioid analgesics. It would be expected that regions with worse socioeconomic and oral health indicators demand a greater use of medications. Hence the results suggest "the inverse care law" ${ }^{\prime \prime 30,31}$ may be present, where poverty can be considered a barrier to access to medications in states with low and high prescription rates.
The correlation coefficients, however, present different results when the data are stratified according to the prescription rates of "low" or "high". In some cases, there was inversion of the relationship direction. In states with high rates of prescriptions, a better HDI, more years of study and more dentists for the population are associated to lower DDD values. A possible explanation for the differences found regarding the dental care plan would be that in states with worse socioeconomic and health indicators having a dental care plan may be a proxy of better socioeconomic status. But possibly in states with better socioeconomic and health indicators, having only the dental care plan would not be a good indicator of better socioeconomic status. ${ }^{32,33}$ Recalling that, as described in the methodology, this covariate concerns population proportion with some plan only for dental care, that is, we are not analysing medical plan.

The fact that the oral health conditions of the seven states with high opioid prescription rates are different from the profile of the other states could explain the differences between the two groups. ${ }^{28,29}$ The use of health services results from several interacting factors, but socioeconomic factors play an essential role on the provision of health services and the possibility of 
the population using this health service. ${ }^{34,35,36}$ Another explanation could be the difference in the quality of the oral health care and the knowledge about opioid prescription among dentists in these two groups of states. ${ }^{29}$ Oral diseases disproportionally affect disadvantaged populations placing an additional disease burden on these populations. Thus, the distribution of the use of these drugs according to region reflects existing inequalities among society produced within the social framework. As well as access to health services, oral health and general health are directly related to socioeconomic factors. ${ }^{34,35,36}$

It is not possible to affirm if there was misuse of opioids in states with higher rates. A separate study at the individual level with access to the reason for prescription is required. However, in population terms, the results suggest that access to this class of drugs can be favoured or opposed according to nonclinical factors. Regions with the highest demands in oral health ${ }^{37}$ were composed of states with lower DDDs. Thus, evaluating the distribution of DDDs according to region can help understand how different approaches and strategies may be necessary within the same national territory. There may be certain barriers to access opioids in regions with extremely low values ${ }^{10}$, which are not desirable, since pain can negatively impact quality of life. In contrast, high values may expose the population to risks of adverse effects. ${ }^{7,38}$ Given this, the surveillance system working together with universities and regional dental councils plays an important role in monitoring these regional differences and thus contributing to the rational use of opioids by dentists.

Regarding the limitations, the entire process of selling and dispensing these drugs is monitored by SNGPC, but it was not possible to identify the reason for the prescription of these drugs in the system. Brazilian legislation does not require that the International Classification of Diseases (ICD) and prescription purpose data to be included in prescription orders of opioid analgesics. The use of secondary data in studies may have methodological problems of data identification and reliability. Results indicated the need for further studies and the format of the current database limited some analysis. It is also important to point out that despite we analysed the most up-todate dataset available for dental prescriptions from the Brazilian Health Regulatory Agency, some increasing in opiate consumption in most recent years may occur, as identified in Brazil ${ }^{39}$ other countries. ${ }^{8}$

In conclusion, the amount of opioid analgesics prescribed by Brazilian dentists showed large differences among Brazilian states and those differences may be associated to non-clinical factors. The clinical implications of these findings are that may be necessary to formulate public policies with different approaches for the country because the regional differences. Prescription drug monitoring programs and continuing education for the prescriber could be implemented and increased in the country. Further studies will be necessary to identify individually related factors to opioids prescribed by dentists.

\section{Acknowledgements}

We thank the Agência Nacional de Vigilância Sanitária - ANVISA for providing access to the database, Boston University Henry M. Goldman School of Dental Medicine for all support provided during the internship of Lino PA, Coordenação de Aperfeiçoamento de Pessoal de Nivel Superior - CAPES through the Programa de Doutorado-sanduíche no Exterior - PDSE (88881.133270/2016-01) and the Conselho Nacional de Desenvolvimento Científico e Tecnológico - CNPq (307617/2015-7).

\section{References}

1. Kassebaum NJ, Smith AG, Bernabé E, Fleming TD, Reynolds AE, Vos T, et al. Global, regional, and national prevalence, incidence, and disability-adjusted life years for oral conditions for 195 countries, 1990-2015: a systematic analysis for the global burden of diseases, injuries, and risk factors. J Dent Res. 2017 Apr;96(4):380-7. https://doi.org/10.1177/0022034517693566

2. Derry S, Moore RA, McQuay HJ. Single dose oral codeine, as a single agent, for acute postoperative pain in adults. Cochrane Database Syst Rev. 2010 Apr;(4):CD008099. https://doi.org/10.1002/14651858.CD008099.pub2 
3. Santini MF, Rosa RA, Ferreira MB, Fischer MI, Souza EM, Só MV. Comparison of two combinations of opioid and non-opioid analgesics for acute periradicular abscess: a randomized clinical trial. J Appl Oral Sci. 2017 Sep-Oct;25(5):551-8. https://doi.org/10.1590/1678-7757-2016-0407

4. Hempenstall K, Nurmikko TJ, Johnson RW, A'Hern RP, Rice AS. Analgesic therapy in postherpetic neuralgia: a quantitative systematic review. PLoS Med. 2005 Jul;2(7):e164. https://doi.org/10.1371/journal.pmed.0020164

5. World Health Organization - WHO. Persisting pain in children package: WHO guidelines on the pharmacological treatment of persisting pain in children with medical illnesses. Geneva: World Health Organization; 2012 [cited 2019 Feb 10] Available from: http://apps.who.int/ iris/bitstream/handle/10665/44540/9789241548120_Guidelines.pdf;isessionid=5E480BD0B44510DE9611C635D8E5C6E2?sequence=1

6. Hollingworth SA, Chan R, Pham J, Shi S, Ford PJ. Prescribing patterns of analgesics and other medicines by dental practitioners in Australia from 2001 to 2012. Community Dent Oral Epidemiol. 2017 Aug;45(4):303-9. https://doi.org/10.1111/cdoe.12291

7. Morin KA, Eibl JK, Franklyn AM, Marsh DC. The opioid crisis: past, present and future policy climate in Ontario, Canada. Subst Abuse Treat Prev Policy. 2017 Nov;12(1):45. https://doi.org/10.1186/s13011-017-0130-5

8. King NB, Fraser V, Boikos C, Richardson R, Harper S. Determinants of increased opioid-related mortality in the United States and Canada, 1990-2013: a systematic review. Am J Public Health. 2014 Aug;104(8):e32-42. https://doi.org/10.2105/AJPH.2014.301966

9. King NB, Fraser V. Untreated pain, narcotics regulation, and global health ideologies. PLoS Med. 2013;10(4):e1001411. https://doi.org/10.1371/journal.pmed.1001411

10. Berterame S, Erthal J, Thomas J, Fellner S, Vosse B, Clare P, et al. Use of and barriers to access to opioid analgesics: a worldwide, regional, and national study. Lancet. 2016 Apr;387(10028):1644-56. https://doi.org/10.1016/S0140-6736(16)00161-6

11. Agência Nacional de Vigilância Sanitária - Anvisa. Sistema Nacional de Gerenciamento de Produtos Controlados - SNGPC. Brasília, DF: Agência Nacional de Vigilância Sanitária; 2018 cited 2018 May 5]. Available from: http://portal.anvisa.gov.br/sngpc

12. Lima L, Sweeney C, Palmer JL, Bruera E. Potent analgesics are more expensive for patients in developing countries: a comparative study. J Pain Palliat Care Pharmacother. 2004;18(1):59-70. https://doi.org/10.1080/J354v18n01_05

13. Landmann-Szwarcwald C, Macinko J. A panorama of health inequalities in Brazil. Int J Equity Health. 2016 Nov;15(1):174. https://doi.org/10.1186/s12939-016-0462-1

14. World Health Organization - WHO. Collaborating Centre for Drug Statistics Methodology. ATC classification and DDD assignment. Oslo: World Health Organization; 2017 [cited 2018 Mar 3]. Available from: https://www.whocc.no/

15. Instituto Brasileiro de Geografia e Estatística - IBGE. Population 2012. Rio de Janeiro: Instituto Brasileiro de Geografia e Estatística; 2018 [cited 2018 Feb 2]. Available from: https://www.ibge.gov.br/estatisticas/sociais/populacao.html

16. Hutchinson JM, Patrick DM, Marra F, Ng H, Bowie WR, Heule L, et al. Measurement of antibiotic consumption: a practical guide to the use of the anatomical thgerapeutic chemical classification and definied daily dose system methodology in Canada. Can J Infect Dis. 2004 Jan;15(1):29-35. https://doi.org/10.1155/2004/389092

17. Programa das Nações Unidas para o Desenvolvimento, Fundação João Pinheiro, Instituto de Pesquisa Econômica Aplicada. Atlas do desenvolvimento humano no Brasil. Brasília, DF: Programa das Nações Unidas para o Desenvolvimento; 2013 [cited 2018 mar 03]. Available from: http://www.atlasbrasil.org.br/2013/

18. Instituto Brasileiro de Geografia e Estatística - IBGE. Pesquisa Nacional de Saúde 2013: Percepção do estado da saúde, estilos de vida e doenças crônicas: Brasil, grandes regiões e unidades da federação. Rio de Janeiro: Instituto Brasileiro de Geografia e Estatística; 2017 [cited 2018 Mar 3]. Available from: https://ww2.ibge.gov.br/home/estatistica/populacao/pns/2013/

19. cfo.org.br. [homepage from the Internet]. Bras?lia: Brasil. Conselho Federal de Odontologia - CFO. Relat?rios do CFO. Sistema de Cadastro; 2017. Available from: http://cfo.org.br/website/

20. Ponizovsky AM, Marom E, Zeldin A, Cherny NI. Trends in opioid analgesics consumption, Israel, 2000-2008. Eur J Clin Pharmacol. 2011 Feb;67(2):165-8. https://doi.org/10.1007/s00228-010-0932-0

21. Schubert I, Ihle P, Sabatowski R. Increase in opiate prescription in Germany between 2000 and 2010: a study based on insurance data. Dtsch Arztebl Int. 2013 Jan;110(4):45-51. https://doi.org/10.3238/arztebl.2013.0045

22. Fischer B, Jones W, Urbanoski K, Skinner R, Rehm J. Correlations between prescription opioid analgesic dispensing levels and related mortality and morbidity in Ontario, Canada, 2005-2011. Drug Alcohol Rev. 2014 Jan;33(1):19-26. https://doi.org/10.1111/dar.12089

23. Garcia del Pozo J, Carvajal A, Viloria JM, Velasco A, Garcia del Pozo V. Trends in the consumption of opioid analgesics in Spain. Higher increases as fentanyl replaces morphine. Eur J Clin Pharmacol. 2008 Apr;64(4):411-5. https://doi.org/10.1007/s00228-007-0419-9

24. Lam KK, Kunder S, Wong J, Doufas AG, Chung F. Obstructive sleep apnea, pain, and opioids: is the riddle solved? Curr Opin Anaesthesiol. 2016 Feb;29(1):134-40. https://doi.org/10.1097/ACO.0000000000000265

25. Overholser BR, Foster DR. Opioid pharmacokinetic drug-drug interactions. Am J Manag Care. 2011 Sep;17 Suppl 11:S276-87.

26. Dassanayake T, Michie P, Carter G, Jones A. Effects of benzodiazepines, antidepressants and opioids on driving: a systematic review and meta-analysis of epidemiological and experimental evidence. Drug Saf. 2011 Feb;34(2):125-56. https://doi.org/10.2165/11539050-000000000-00000

27. Lima MG, Álvares J, Guerra AA, Costa EA, Guibu IA, Soeiro OM, et al. Indicators related to the rational use of medicines and its associated factors. Rev Saude Publica. 2017 Nov;51 suppl 2:23s. https://doi.org/10.11606/S1518-8787.2017051007137 
28. Stopa SR, Malta DC, Monteiro CN, Szwarcwald CL, Goldbaum M, Cesar CL. Use of and access to health services in Brazil, 2013 National Health Survey. Rev Saude Publica. 2017 Jun;51 suppl 1:3s. https://doi.org/10.1590/s1518-8787.2017051000074

29. Reis CM, Mambrini JV, da Matta-Machado AT, Amaral JH, Werneck MA, Abreu MH. Primary dental care evaluation in Brazil: an item response theory approach. J Public Health Dent. 2017 Sep;77(4):317-24. https://doi.org/10.1111/iphd.12210

30. Hart JT. The inverse care law. Lancet. 1971 Feb;1(7696):405-12. https://doi.org/10.1016/S0140-6736(71)92410-X

31. Dehmoobadsharifabadi A, Singhal S, Quiñonez C. Investigating the "inverse care law" in dental care: A comparative analysis of Canadian jurisdictions. Can J Public Health. 2017 Mar;107(6):e538-44. https://doi.org/10.17269/CJPH.107.5454

32. Cascaes AM, Camargo MB, Castilhos ED, Silva LE, Barros AJ. Private dental insurance expenditure in Brazil. Rev Saude Publica. $2018 ; 52: 24$. https://doi.org/10.11606/S1518-8787.2018052000340

33. Macarevich A, Pilotto LM, Hilgert JB, Celeste RK. User satisfaction with public and private dental services for different age groups in Brazil. Cad Saude Publica. 2018 Feb;34(2):e00110716. https://doi.org/10.1590/0102-311x00110716

34. Almeida AP, Nunes BP, Duro SM, Facchini LA. Socioeconomic determinants of access to health services among older adults: a systematic review. Rev Saude Publica. 2017 May;51(0):50. https://doi.org/10.1590/s1518-8787.2017051006661

35. Koh HK, Piotrowski JJ, Kumanyika S, Fielding JE. Healthy people: a 2020 vision for the social determinants approach. Health Educ Behav. 2011 Dec;38(6):551-7. https://doi.org/10.1177/1090198111428646

36. Watt RG. Social determinants of oral health inequalities: implications for action. Community Dent Oral Epidemiol. 2012 Oct; 40 Suppl 2:44-8. https://doi.org/10.1111/j.1600-0528.2012.00719.x

37. Ministério da Saúde (BR). Secretaria de Atenção à Saude. Secretaria de SB Brasil 2010: Pesquisa Nacional de Saúde Bucal: resultados principais. Brasília, DF: Ministério da Saúde; 2012.

38. Jones CM, Paulozzi LJ, Mack KA. Sources of prescription opioid pain relievers by frequency of past-year nonmedical use United States, 2008-2011. JAMA Intern Med. 2014 May;174(5):802-3. https://doi.org/10.1001/jamainternmed.2013.12809

39. Krawczyk N, Greene MC, Zorzanelli R, Bastos Fl. Rising trends of prescription opioid sales in contemporary Brazil, 2009-2015. Am J Public Health. 2018 May;108(5):666-8. https://doi.org/10.2105/AJPH.2018.304341 